This item was submitted to Loughborough's Research Repository by the author.

Items in Figshare are protected by copyright, with all rights reserved, unless otherwise indicated.

\title{
Re-envisioning the role of benefits realisation in a world dominated by robots
}

PLEASE CITE THE PUBLISHED VERSION

http://dx.doi.org/10.1109/RCIS.2016.7549321

PUBLISHER

(c) IEEE

VERSION

AM (Accepted Manuscript)

\section{PUBLISHER STATEMENT}

This work is made available according to the conditions of the Creative Commons Attribution-NonCommercialNoDerivatives 4.0 International (CC BY-NC-ND 4.0) licence. Full details of this licence are available at: https://creativecommons.org/licenses/by-nc-nd/4.0/

\section{LICENCE}

CC BY-NC-ND 4.0

\section{REPOSITORY RECORD}

Doherty, Neil. 2019. "Re-envisioning the Role of Benefits Realisation in a World Dominated by Robots". figshare. https://hdl.handle.net/2134/23620. 


\section{Re-envisioning the role of Benefits Realisation in a world dominated by Robots}

\author{
Professor Neil F. DOHERTY \\ The Business School, \\ Loughborough University, \\ Loughborough, Leics, \\ N.F.Doherty@lboro.ac.uk
}

\begin{abstract}
In recent years there has been a great deal of academic and practitioner interest in the role of 'benefits realisation management' [BRM] approaches, as a means of proactively leveraging value from IT investments. However, as automated technologies are increasingly being introduced on the basis that they deliver more cost-efficient solutions than their human counterparts, important questions needs to be asked about how value should be defined in a world that is increasingly dominated by robots. Consequently, the aim of this work-in-progress paper is to explore, using the literature, how automated systems continue to replace the human agent, in a growing number of organisational contexts, before looking at how tools such as benefits realisation, may need to be modified to ensure that there is an appropriate balance between the social and the technical in the planning of future IS/IT investments. In so doing, this essay seeks to develop a provisional research agenda, which will hopefully help to shape future contributions to the domains of benefits realisation, sociotechnical approaches and IT evaluation.
\end{abstract}

Key Words: Robots; automation; socio-technical design, IT evaluation; benefits realisation management.

\section{INTRODUCTION}

It now seems unthinkable for organisations to consider designing their business processes, without deploying the considerable capabilities of information technology, to ensure that their business processes can be enacted in the most efficient and effective manner. Unfortunately, despite growing ubiquity of information technology, within the organisational context, the path to computerisation is not always smooth, and considerable amounts of time, money, effort and opportunity are still wasted upon software investments that ultimately fail to deliver meaningful benefits [1]. While estimates of the level of IT failure may vary, over the past forty years they have tended to remain uncomfortably high. For example, whilst in the late 1970 s, it was estimated that only $20 \%$ of projects 'achieved something like their intended benefits' [2], a far more recent study [3] suggests that the situation is little better, as it concluded that $74 \%$ of business IT projects still failed to deliver their expected value. Consequently, studies which seek to assess the determinants of systems failure, and find more reliable and effective ways of managing business software projects, have remained an enduring staple of the business and computing literatures $[4 ; 5 ; 6]$.
So what do these prior studies tell us about the major causes and implications of information systems failure? A common insight has been that software may often underperform, or even be rejected, because the designers seek to harness it to existing business process designs, and traditional patterns of employee behaviour [7]. As Eason [2] observed, all too often systems fail, because system developers aren't aware that it is through organisational change, rather than through a technology's functionality, that benefits are most commonly leveraged. Systems also fail because they often trigger unintended human and organisational impacts that users may ultimately perceive to be unacceptable [8]. Either way, it is now widely acknowledged that unless systems designers find effective ways to manage the human and organizational impacts of their software applications, then the unacceptably high levels of systems' failure or under performance are unlikely to decline $[9 ; 10]$. Consequently, there has been a great deal of interest in software development approaches that explicitly seek to simultaneously design and align the social and the technical aspects of the resultant system $[4 ; 11]$. In recent years, one particular class of socio-technical approach - benefits realisation management [1] - has been attracting a growing amount of attention as it has the potential to both address the needs of the users, at the micro level, and the needs of the business, at a more macro level [12].

Whilst this broad stream of socio-technical research has sought to explicitly explore how the technology can best be facilitated through human agency, other streams of research have been highlighting the very real danger of new technologies either completely replacing the human agent [13] or significantly downgrading their contributions to IT-enabled business processes [14]. In his book the Rise of the Robots, Martin Ford [13] raises the question as to whether the rapid advances in artificial intelligence, robotics and automation, experienced in recent years, portend a future in which robots and software greatly reduce the need for human workers? He [13] provides a wealth of economic data, relating to stagnant wages, the underemployment of graduates, diminishing job creation and the rise of part-time employment, to argue that: 'robots and self-service technologies [will] eat away at lowwage jobs, whilst increasingly intelligent algorithms threaten higher skill occupations' [p. 61]. It is not so much the erosion of jobs that concerns Simon Head in his book Mindless, but the potential of IT systems to create a world of top-down control in which the performance employees of continuously monitored, and they have very control of how and when they 
make their increasingly regimented contributions to ITenabled business processes.

Against this backdrop, the aim of this paper is to present a research agenda, which explores how benefits realisation may be re-envisioned to play a positive role in ensuring that the human agent can retain a substantive and productive role in future IT-enabled business processes. The paper progresses by critically reviewing the work of contemporary authors who highlight the challenges posed by the increasing automation of business processes, and the downgrading of the role of the human agent. The core principles of the benefits realisation management approach are then introduced, before critically evaluating its fitness for purpose in a future world increasingly dominated by automated processes and robotics. The paper finishes by demonstrating how the benefits realisation management approach might evolve to help promote the role of the worker, in this IT-enabled working environment, before presenting an outline a research agenda for helping this rather more positive future come to pass.

\section{THE IMPACT OF AUTOMATION AND ROBOTICS ON THE HUMAN AGENT}

This section reviews the existing literature with respect to the future context in which business processes are likely to operate, paying particular attention to the rise of the robot and the downgrading of the role of human agent. However, before looking to the future, a brief review will be presented of how the impact of IT on the worker, has been viewed over the past two decades. In reviewing these literatures, the motivations and academic justification for this research will be established.

\section{A. The Impact of IT on Work: an Historical Perspective}

The serious study of the organizational effect of IT implementations on organizational structures, the design of work and the autonomy of managers, probably began in the 1950s with Leavitt and Whisler's [15] seminal paper, which predicted that information technologies were likely to: 'change the role and scope of middle managers' and encourage 'large organisations to recentralise'. Since then, there has been a steady flow of empirical and conceptual studies that have explored the impact of a variety of types and configurations of information technology on a range of characteristics relating to the design and structuring of organisational work $[16 ; 17]$. As information technology has become an increasingly ubiquitous and integral part of the organizational landscape, a debate has raged over whether from the employees' perspective, IT should be viewed as a friend or foe. Either way, as Zuboff [18] notes, this widespread adoption of information technology is not 'neutral', as it embodies 'essential characteristics that are bound to alter the nature of work within factories and offices, and among workers, managers and professionals' [p. 7].

Let's look a little more closely at each of these polarised positions On one side of this debate, we have found many commentators who have argued that IT has the potential to empower employees, and in so doing, both enhance their performance, whilst also making their work more intrinsically rewarding. For example, Psoinos et al [19] have argued that employees may be enabled to develop more autonomous and effective ways of working through the tailored provision of appropriate information, directly to their desk-tops. By contrast, many other researchers have argued that information technology's primary organisational roles have been those of deskilling and constraining employee's degrees of freedom [20]. These commentators are concerned that information systems may provide the ideal tool for the monitoring and regulation of employee performance, and are therefore typically associated with the 'the desire to realise and maintain control' [21, p. 55].

Whilst looking backwards we find almost overwhelming support for the proposition that organisational IT significantly impacts the design and experience of work, there has been a vibrant debate as to whether on balance such impacts should be viewed positively or negatively. By contrast, when looking to the future, there appear to be rather more pessimists than optimists.

\section{B The Downgrading of the Human Agent.}

Bringing the debate right up to date, Loebbecke and Picot [22] argue that information technology continues to reshape existing work practices and organizational structures, but in ever more radical ways. As McAfee \& Brynjolfsson [23] note, it's not just the power of software that is putting jobs under pressure, it's the enormous versatility of technology that gives it the potential to reshape or replace just about every single task, in nearly every organisational context.

Head [14] demonstrates, using a variety of contemporary business examples, how many organisations are using IT to enforce 'desirable' worker behaviours, while simultaneously monitoring their actions and performance at a very detailed level. For example, Head [14] provides an insight into the working life of an Amazon employee, at one of their large logistics centres, where each is tagged, so that their every movement can be monitored using GPS style tracking. Employees will then receive text messages from their managers, in real time, if it is felt that they are in danger of failing to meet their highly challenging targets. In a similar vein, Head [14] also reports on the experiences of Walmart employees, whose every action is specified and monitored by the "Task Master" system: 'the system tells employees what to do, how long they have to do it, and whether they have met their target times '[p. 31]'.

It's not just the shop floor worker, whose roles and performance are being ever more closely scrutinised and their actions dictated by business systems, as managers and executives are also being monitored. As McAfee and Brynjolfsson [24] note, with the rapid deployment of the enterprise system:

'management becomes a distinctly less comfortable profession-more unforgiving of mistakes, faster to weed out low performers. Even those executives who 
are prepared will not necessarily survive the inevitable turbulence' [p.98].

\section{The Rise of the Robots}

Many commentators are now arguing that we are moving into an era in which smart machines and business softwares will not just have the potential to enhance the productivity of workers, but that they will become viable, and cost-effective, substitutes for traditional labour. As Ford [13] notes:

\section{'IT's unique ability to scale machine intelligence across organisations in a way that will substitute for workers, and its propensity to create winner takes all scenarios, will have dramatic implications for both the economy and society'. [p. 82]}

It has been argued [13] that most of the work undertaken within organisations is fundamentally routine in nature, and therefore susceptible to complete or partial automation. Initially, the focus of senior managers' desire to cut costs, whilst improving efficiency and assuring quality, was the unskilled or semi-skilled worker, who inhabited offices, factories and warehouses, Consequently, most business processes, that are enacted in such domains, are now routinized and automated to the extent that there is little room for human discretion. Moreover, through this rapidly unfolding strategy of automation and standardisation, the need for the unskilled human component in the business process is greatly diminished [13]. A highly tangible example of the march of automation was the recent announcement [25] by Foxconn's CEO - Terry Gou - that his organization will probably use robots and automation to complete 70 percent of its assembly line work, within the next three years.

The big idea that has started to gain traction in recent years, and which is likely to gain pace in the future, is that even the most sophisticated jobs, such as the work of brain surgeons, engineers and lawyers can also be broken down into a series of discrete tasks that are relatively predictable and are likely to be enacted over some broadly predictable time frame. Consequently, in the years to come, the jobs of highly trained and educated professionals might be under the same level of threat, as many unskilled or semi-skilled jobs are today [26].

It's not just the highly trained specialists whose livelihoods are being challenged, as large numbers of managers are now also finding their positions in the organisational hierarchy under threat from ever more sophisticated business software. Decision-making used to be the preserve of the managerial classes, and managers were typically, well educated, highly trained and very well rewarded for their efforts on behalf of their host organisations. However, as Markus [27] notes, we can see increasing evidence of a large-scale shift to decision automation. Increasingly, sophisticated software fosters machine-based interpretation of data [22], which enables many decisions to be made autonomously by systems. The likelihood is that with the growth of disciplines such as business analytics, machine learning and artificial intelligence, the scope for automated decision-making will increase greatly, and such software will become deeply embedded in a vast array of value-adding businesses processes.

It can be argued that all types of job from the most lowly manual occupations through to the most complex and sophisticated specialist positions now face a growing threat of redundancy through the rise of the robot and other forms of automated system, but what proportion of occupations are now at threat? Although it is difficult to quantify this threat, Frey and Osborne [28] argue that the rapid automation of business processes already puts $47 \%$ of US jobs at risk, though mainly at the unskilled and semi-skilled end of the employment spectrum However, it has been argued [26] that, when taking account of recent advances in automation and artificial intelligence, it is possible to infer that over half of all jobs, including many which can be classified as skilled, specialist or managerial, are already under threat of being made redundant.

\section{A Critique of the Literature}

From this provisional review of the literature, it would appear that a considerable body of work has evolved with regard to the likely impact of new technologies and softwares on the downgrading of the role of the human agent in the enactment of future business processes. However, by contrast, little attention has been paid, thus far, as to how traditional systems development and evaluation approaches will need to change, in order to cope with this dramatically changing organisational landscape. Against this backdrop, the remainder of this paper seeks to present a provisional assessment of how socio-technical approaches, and in particular tools such as benefits realisation, may need to be modified to stay relevant in such an environment. In so doing, a research agenda is presented that seeks to address the ways in which BRM approaches will need to be tailored, to ameliorate some of the most negative impacts of automation, by ensuring that there is an appropriate balance between the social and the technical in the planning of future IS/IT investments.

\section{SOCIO-TECHNICAL VIEWS OF THE ORGANISATION}

As noted in this paper's introduction, the incidence of information systems failure has remained far too high, for far too long. Moreover, it has been widely acknowledged in the literature that the primary cause of failure has been systems developers' inability to effectively cope with the social dimension, rather than the technical dimension, of business computing. As Clegg et al. [29] have noted:

'Lack of attention to the human and organizational aspects of IT is a major explanatory factor (with regard to the high levels of systems failure) and is manifest in poor management generally, poor project management, poor articulation of user requirements, inadequate attention to business needs and goals, and a failure to involve users appropriately'. 
Consequently, success is often predicated upon the ability of software development teams to proactively redesign organisational activities and business processes, to ensure that the host business has been explicitly tailored to make best use of its new investment in IT [9; 10]. Against this backdrop, the broad aim of the remainder of this section is to provide a general overview of socio-technical approaches to systems development, before homing in on one specific approach, benefits realisation management, as it may be particularly well suited to be re-envisioned for use in a business world increasingly dominated by robots and fully automated systems. After critically reviewing these literatures, this section will conclude with a summary of the challenges to socio-technical theory posed by higher level of automation and robotics.

\section{A Socio-technical Approaches to Systems Development.}

When implemented in any organisational context, information systems tend to become social, rather than technologically determined, constructs, as they may be interpreted and appropriated in multifarious ways, throughout their operational lives [30]. The implication of this 'social constructivist' perspective [31] is that very similar organisations can experience radically 'different outcomes with the same technology' [p. 69]. Consequently, systems developers must move away from their traditional, deterministic views of the IT artifact, and embrace a sociotechnical perspective that actively encourages systems developers to jointly design the social and technical elements of a system [10].

Against this backdrop, the need for approaches to systems development, implementation and operations that pay equal attention to the social and technological dimensions of information systems has never been greater. To provide a richer understanding of principles upon which socio-technical thinking is based, Eason [32] proposed a set of ten distinct propositions. Of these ten propositions, seven have been presented in table 1, as they provide a helpful overview of socio-technical thinking, for the interested reader, and they have a specific resonance, in the context of this study, as they all emphasis that organisational goals will only be achieved if technological innovation is complemented by appropriate organisational change.

It has long been a central tenet of socio-technical thinking, that it is rarely possible to design business software, which can be guaranteed to deliver specified organisational outcomes, unless the organisational context in which the software will operate is also proactively redesigned [10]. However, even when an organisational context has been proactively redesigned, a very significant problem facing the systems developer and the systems sponsor is that the impacts and outcomes of introducing a new information system, and the reactions of members of the user community, cannot generally be predicted at the project's outset. Although in his ninth proposition, Eason [32] highlights the need for exploiting technologies over time, the main focus of socio-technical theorists has typically been on the redesign of social contexts, in advance of implementation.

By contrast, the benefits realisation literature has tended to have a far more explicit focus on the need to customise technologies, and redesign their host contexts, over time, in order to realise the full value of any investment, as noted by Doherty et al [33], and further explored in the following section, the realisation of meaningful benefits from any newly implemented technology is 'an on-going journey, rather than a destination' [p. 4].

\section{B Benefits Realisation Management.}

One of the most promising approaches that can be used to achieve a more harmonious relationship between IT and the social contexts in which it is intended to operate, is through the application of benefits realisation management.

Table 1: Key Propositions from Socio-Technical Theory [32]

\begin{tabular}{cl}
\hline Proposition No. & Proposition Description \\
\hline$\# 1$ & $\begin{array}{l}\text { The successful exploitation of IT depends upon the ability and willingness of the employees of an } \\
\text { organisation to use the appropriate technology to engage in worthwhile tasks' [p.44]. } \\
\text { The design target must be to create a socio-technical system capable of serving organisational goals, not } \\
\text { to deliver a technical system capable of delivering a technical service' [p.45]. } \\
\text { The effective exploitation of socio-technical systems depends upon the adoption of a planned process of } \\
\text { (organisational) change [p.46]. } \\
\text { The design of effective socio-technical systems will depend upon the participation of all relevant } \\
\text { stakeholders [p. 46]. } \\
\text { Major benefits will only result if the socio-technical developments are directed at major organisational } \\
\text { purposes where there are opportunities to be taken or problems to be resolved [p.47]. } \\
\text { IT systems must be designed to serve the functional needs of the organisation by serving the functional } \\
\text { needs of individual users in a usable and acceptable way [p.47]. } \\
\text { The exploitation of the capabilities of information technology can only be achieved by a progressive, } \\
\text { planned form of evolutionary growth [p.48]. }\end{array}$ \\
\end{tabular}


Benefits realisation management [BRM] has been defined as 'the process of organising and managing, such that the potential benefits arising from the use of IT are actually realised' [34]. Although BRM is still in its relative infancy, it offers real hope of a practical solution to the socio-technical conundrum facing systems designers, as it presents a practical set of tools, which can help ensure that the system meets the needs of individual users, whilst also, and most importantly, explicitly supporting the goals of the host organisation.

Benefits realisation management [BRM] approaches have typically been justified on the basis that they provide a very strong counterpoint to the traditional business case, which can be criticised because any explicit emphasis on benefits, inherent in the business case, soon fades away, once approval has been granted, [32]. By contrast, benefits realisation approaches aim to place the realisation of business value at the forefront of all decisions relating to the design, implementation and operation of any application of IT. Whilst it is beyond the scope of this paper, to present a detailed appraisal of BRM approaches, the following three key facets, provide a useful overview [12]:

1) Active management: It is not enough to simply define all project outcomes in terms of the benefits to be delivered; their realisation has to be actively planned and managed;

2) Realisation through regular review: To ensure that any software delivers real business value, its performance and impacts must be reviewed, at regular intervals, from inception through to de-commissioning;

3) Shared responsibility: Because of its strong focus on corporate strategies and organizational change, benefits realization is a responsibility that must be shared between all managerial stakeholders.

\section{Challenges to Socio-technical Approaches}

Two important and tightly coupled views have pervaded much of the information systems literature, over the past twenty years. The first is that Information technology cannot, be viewed as a deterministic artefact, as it does not generally behave in a well ordered and predictable manner [35]. The second is that organizational stakeholders have the potential to interpret, appropriate and ultimately shape their information systems in a wide variety of ways [30]. If the human actor has the power to modify, appropriate or even subvert the intended roles of business systems, then it could be legitimately argued that there is a pressing need to deploy socio-technical approaches, to help ensure that the users' needs are explicitly accounted for prior to systems implementation. However, in a business world that will increasingly be dominated by highly automated business processes, both of these suppositions will increasingly be called into question.

The alternative perspective that I shall seek to develop in the following section is that socio-technical approaches, and in particular, benefits realisation management must be tailored so that they continue to find value-adding roles for the human agent in the increasingly automated business process of the future.

\section{DISCUSSION: THE ROLE OF BENEFITS REALISATION IN THE AUTOMATED ORGANISATION}

In their extensive review of the literature, with regard to the business value of IT, Melville et al [36] conclude that there are two primary channels through which new applications of software may deliver business value:

1) Efficiency benefits: this strategy emphasises an internal orientation, in which cost cutting and productivity enhancements are the primary objectives;

2) Effectiveness benefits: this approach adopts an external orientation, which explicitly seeks to apply IT in ways that deliver benefits to the customers, in terms of enhanced service or satisfaction.

The rapid move towards higher levels of automation, through the wide-spread adoption of robots, clearly has great potential to deliver very significant efficiency benefits. However, there is a very real danger that in adopting automation strategies that have a very distinctive internal, cost efficiency orientation, organisations may lose sight of other aspects of their strategy, and in particular, those that are important to their customers, and help them maintain their competitive position. Indeed, Afflerbach [37] argues that organisations already have an inbuilt, 'irrational' bias against effectiveness projects, which seek to increase revenues, rather than reducing costs, and, too often, therefore they miss out on potentially rewarding investment opportunities.

In a business world in which automation will increasingly feature upon many managerial agendas, it can be argued that organisations must not lose sight of opportunities to improve their effectiveness through the adoption of technology, and this may require approaches that still need a careful balance of human and technical capabilities. The BRM approaches, presented in this paper, may have a very constructive role to play in this context as they explicitly seek to align technology investments with organisational strategy, so they are very well suited to delivering effectiveness benefits. Moreover, even in circumstances in which the primary goal is to increase efficiency through business process automation, then BRM may still prove useful in identifying those elements of the process in which the human agent can add value. In terms of a provisional research agenda for BRM, in a world increasingly dominated by robots, the following are all areas that we are actively starting to explore:

1. To identify ways of modifying existing BRM tools to reflect the complex interplay between automated systems and the human agents, with whom they will interact;

2. To develop new BRM approaches that can both account for, and help align, the needs and aspirations of workers, and the strategic goals of the host organisation;

3. To explore ways in which the human agent can retain a substantive, productive and value-adding role in future IT-enabled business processes;

4. To explore how organisations can be encouraged to recognise that systems that deliver effectiveness benefits are as important to their long-term survival, as those that deliver efficiency benefits; 
Whilst this is clearly not a definitive agenda for studies in this increasingly important and challenging research domain, these are all areas in which we feel that there are very significant theoretical and practical contributions to be delivered.

\section{CONCLUDING REMARKS}

Economic historians view the earnings distribution as the product of a race between changing technology, which widens the distribution, and education, which narrows the distribution [38]. In a future business world in which rapid technological development and deployment, will pose an unprecedented threat to jobs, income equality and potentially even social cohesion, then it can be argued that the need for education has never been greater. Indeed, it can be argued that businesses of all shapes and sizes will need to be educated about the unique capabilities of their employees, and how these can best be developed and tailored to complement information technologies in value-adding business processes.

\section{References}

[1] Peppard J. \& Ward J. "Unlocking sustained business value from IT investments", California Management Review, Fall, 2005, pp. 52-69.

[2] Eason, K. D., Information Technology and Organizational Change, 1988, Taylor \& Francis, London.

[3] Shpilberg, D., Berez, S,. Puryear R. \& S. Shah "Avoiding the alignment trap in information technology," MIT Sloan Management Review, Vol. 49, No. 1, 2007

[4] Eason, K.D. "The process of introducing information technology", Behaviour \& Information Technology, Vol. 1, No. 2, 1982, pp.197-213.

[5] Doherty, N. F. and King, M. "An investigation of the factors affecting the successful treatment of organizational issues in systems development projects", European Journal of Information Systems, Vol. 10, 2001, pp. 147-160.

[6] Nelson, R.R. "IT project management: infamous failures, classic mistakes, and best practices", MIS Quarterly Executive, Vol. 6, No. 2 pp. 2007, pp. 67-78.

[7] Ward, J. Daniel, E. and Peppard, J. "Building a better business case for IT Investments, MIS Quarterly Executive, Vol. 7, No. 1, 2008, pp 1-14

[8] Martinsons, M.G. and Chong, P.K. "The influence of human factors and specialist involvement on information systems success, Human Relations, Vol. 52, No.1, 1999, pp. $123-152$.

[9] Doherty, N. F., King, M., \& Al-Mushayt, O. "The impact of inadequacies in the treatment of organizational issues on information systems development projects", Information and Management, Vol. 41, No. 1,2003, pp. $49-62$.

[10] Clegg, C. W., Gray, M. O. \& Waterson, P. E. (2000) "The 'Charge of the Byte Brigade' and a socio-technical response", International Journal of Human-Computer Studies, Vol. 52, 2000, pp. 235-251.

[11] Mumford, E. Effective Systems Design and Requirements Analysis. 1995, Wiley, London, UK.

[12] Doherty, Neil F. "The role of socio-technical principles in leveraging meaningful benefits from IT investments." Applied ergonomics 45.2 (2014): 181-187.

[13] Ford, Martin. Rise of the Robots. Oneworld Publications, 2016.

[14] Head, Simon. Mindless: Why smarter machines are making dumber humans. Basic Books, 2014.

[15] Leavitt, H. J. and T. L. Whisler, "Management in the 1980s." Harvard Business Review, Vol. 36, No.6, 1958, pp 41-48
[16] Simon, H. A. The New Science of Management Decision. 1977, Englewood Cliffs, New Jersey: Prentice Hall.

[17] Sauer, C. and Willcocks, L. "Establishing the business of the future: the role of organizational architecture and information technologies." European Management Journal Vol. 21, No. 4, 2003, pp 497-508.

[18] Zuboff, S. In the age of the smart machine: the future of work and power. 1988, New York: Basic Books.

[19] Psoinos A, Smithson S and Kern T "An Exploratory study of information systems in support of employee empowerment: Constraints and opportunities". Journal of Information Technology Vol. 15, 2000.

[20] Torkzadeh G and Doll WJ "The development of a tool for measuring the perceived impact of IT on work", 1999. Omega, pp. 327-339.

[21] Bloomfield BP and Mclean C., "Beyond the walls of the asylum: information and organisation in the provision of community health services". Information and Organisation, Vol. 13, 2003, pp. 55-84.

[22] Loebbecke, C, \& Picot, A. "Reflections on societal and business model transformation arising from digitization and big data analytics" The Journal of Strategic Information Systems 24.3 (2015): 149-157.

[23] Brynjolfsson, Erik, and Andrew McAfee. Race against the machine: How the digital revolution is accelerating innovation, driving productivity, and irreversibly transforming employment and the economy. Brynjolfsson and McAfee, 2012.

[24] McAfee, Andrew, and Erik Brynjolfsson. "Investing in the IT that makes a competitive difference." Harvard Business Review 86.7/8 (2008): 98.

[25] http://www.pcworld.com/article/2890032/foxconn-expects-robots-totake-over-more-factory-work.html

[26] Elliott, S.W. “Anticipating a Luddite Revival”, Issues in Science and Technology, Spring, 2014, pp.27-36.

[27] Markus, L., "New games, new rules, new scoreboards: the potential consequences of big data", Journal of Information Technology, Vol. 30, No. 1, 2014, pp. 58-59.

[28] Frey, C.B. and Osborne, M.A. "The Future of Employment: How susceptibleare jobs to computerization?" 2013, Oxford: Oxford Martin Programme on the Impacts of Future Technology.

[29] Clegg, C. W., Axtell, C., Damodaran, L., Farbey, B., Hull, R., LloydJones, R., Nicholls, J., Sell, R. \& Tomlinson, C. "Information technology: a study of performance and the role of human and organizational factors", Ergonomics, Vol. 40, No. 9, 1997, pp. 851-871

[30] Orlikowski, W.J., Yates, J. Okamura, K. \& Fujimoto, M. "Shaping electronic communication - the meta-structuring of technology, in the context of use", Organization Science, Vol. 6,No. 4, 1995, pp 423-444.

[31] Leonardi, P. M., S. R. Barley. Materiality and change: Challenges to building better theory about technology and organizing. Information and Organisation, Vol. 18, No. 3, 2008, pp. 159-176.

[32] Eason, K. D., Information Technology and Organizational Change, 1988, Taylor \& Francis, London.

[33] Doherty, N. F. Ashurst, C. \& Peppard, J. "Factors Affecting the Successful Realisation of Benefits from Systems Development Projects: Findings from Three Case Studies", Journal of Information Technology, Vol. 27, No. 1, 2012, pp.1-16.

[34] Ward, J. \& Elvin, R. "A new framework for managing IT-enabled business change", Information Systems Journal, Vol. 9 No. 3, 1999, pp. 197-222.

[35] Grint, K. and Woolgar, S. The Machine at Work. 1997, Polity Press: Cambridge.

[36] Melville, N., Kraemer, K. \& Gurbaxani, V. "Review: IT \& Organisational Performance: An Integrative Model of IT Business Value", MIS Quarterly Vol. 28, No. 2, 2004, pp. 283-322.

[37] Afflerbach, P.. "The Business Value of IT in Light of Prospect Theory." Business \& Information Systems Engineering 57.5, 2015, pp. 299-310.

[38] Goldin, C D and L F Katz, The race between education and technology, 2009, Cambridge, MA: Harvard University Press 